Article

\title{
Exploring the Gelation Mechanisms and Cytocompatibility of Gold (III)-Mediated Regenerated and Thiolated Silk Fibroin Hydrogels
}

\author{
Chavee Laomeephol ${ }^{1,2}$ (D), Helena Ferreira ${ }^{3,4}$, Supansa Yodmuang ${ }^{1,2,5}$, Rui L. Reis ${ }^{3,4,6}$, \\ Siriporn Damrongsakkul ${ }^{1,2,7, *}$ and Nuno M. Neves ${ }^{3,4,6, * \mathbb{D}}$
}

1 Biomedical Engineering Research Center, Faculty of Engineering, Chulalongkorn University, Bangkok 10330, Thailand; chavee.1@student.chula.ac.th (C.L.); Supansa.Y@chula.ac.th (S.Y.)

2 Biomaterial Engineering for Medical and Health Research Unit, Faculty of Engineering, Chulalongkorn University, Bangkok 10330, Thailand

3 3B's Research Group, I3Bs-Research Institute on Biomaterials, Biodegradables and Biomimetics, University of Minho, Headquarters of the European Institute of Excellence on Tissue Engineering and Regenerative Medicine, AvePark-Parque de Ciência e Tecnologia, Zona Industrial da Gandra, 4805-017 Barco, Guimarães, Portugal; helenaferreira@i3bs.uminho.pt (H.F.); rgreis@i3bs.uminho.pt (R.L.R.)

4 ICVS/3B's-PT Government Associate Laboratory, 4806-909 Braga/Guimarães, Portugal

5 Research Affairs, Faculty of Medicine, Chulalongkorn University, Bangkok 10330, Thailand

6 The Discoveries Centre for Regenerative and Precision Medicine, Headquarters at University of Minho, Avepark, 4805-017 Barco, Guimarães, Portugal

7 Department of Chemical Engineering, Faculty of Engineering, Chulalongkorn University, Bangkok 10330, Thailand

* Correspondence: siriporn.d@chula.ac.th (S.D.); nuno@i3bs.uminho.pt (N.M.N.); Tel.: +662-218-6862 (S.D.); +351-253-510-905 (N.M.N.); Fax: +662-218-6877 (S.D.); +351-253-510-909 (N.M.N.)

Received: 8 February 2020; Accepted: 16 March 2020; Published: 18 March 2020

check for updates

\begin{abstract}
Accelerating the gelation of silk fibroin (SF) solution from several days or weeks to minutes or few hours is critical for several applications (e.g., cell encapsulation, bio-ink for 3D printing, and injectable controlled release). In this study, the rapid gelation of SF induced by a gold salt $\left(\mathrm{Au}^{3+}\right)$ as well as the cytocompatibility of $\mathrm{Au}^{3+}$-mediated SF hydrogels are reported. The gelation behaviors and mechanisms of regenerated SF and thiolated SF (tSF) were compared. Hydrogels can be obtained immediately after mixing or within three days depending on the types of silk proteins used and amount of $\mathrm{Au}^{3+} . \mathrm{Au}^{3+}$-mediated SF and $\mathrm{tSF}$ hydrogels showed different color appearances. The color of Au-SF hydrogels was purple-red, whereas the Au-tSF hydrogels maintained their initial solution color, indicating different gelation mechanisms. The reduction of $\mathrm{Au}^{3+}$ by amino groups and further reduction to Au by tyrosine present in SF, resulting in a dityrosine bonding and Au nanoparticles (NPs) production, are proposed as underlying mechanisms of Au-SF gel formation. Thiol groups of the tSF reduced $\mathrm{Au}^{3+}$ to $\mathrm{Au}^{+}$and formed a disulfide bond, before a formation of $\mathrm{Au}^{+}-\mathrm{S}$ bonds. Protons generated during the reactions between $\mathrm{Au}^{3+}$ and SF or tSF led to a decrease of the local $\mathrm{pH}$, which affected the chain aggregation of the SF, and induced the conformational transition of SF protein to beta sheet. The cytocompatibility of the Au-SF and tSF hydrogels was demonstrated by culturing with a L929 cell line, indicating that the developed hydrogels can be promising 3D matrices for different biomedical applications.
\end{abstract}

Keywords: silk fibroin; thiolated silk fibroin; gold; hydrogel; cytocompatibility

\section{Introduction}

Silk fibroin (SF) is a protein-based biopolymer derived from Bombyx mori mulberry silkworms. $\mathrm{SF}$ is the main component presented in silkworm cocoons (about 72-81\%) and another component is a 
glue-like sericin protein that can be eliminated by alkaline treatments. SF is a heterodimeric protein, containing a heavy chain (MW 325 kDa) and a light chain (MW 25 kDa), linked by disulfide bridges. The glycine-alanine repetitive sequences, present in high amount in the heavy chain, are responsible for the formation of beta sheet structure, making SF a natural-derived material with good biodegradability and excellent mechanical properties [1]. Due to its biocompatibility, the high mechanical stability and resistance against several physiological enzymes, SF has a long history of use in biomedical applications, e.g., suture materials [2].

SF fibers obtained from silk cocoons can be readily used, but they have to be dissolved in chaotropic agents to disrupt the hydrogen bonds. By doing this, the ordered beta sheet structures turn into amorphous random coil, and the dissolution of SF fiber is obtained. The SF solution can be further processed into membranes, microparticles, fibers, or porous scaffolds, depending on the specific application envisaged [2]. However, SF solution spontaneously turns into hydrogel within several days or weeks because of the gradual transition to the thermodynamically stable beta sheet structure [3]. This self-assembly characteristic of SF has intrigued many researchers, which have been employing various strategies to control and accelerate the gelation process. Indeed, a short gelation time is crucial for many applications, such as cell-loaded hydrogels or injectable controlled release systems. Crosslinking agents (e.g., glutaraldehyde, carbodiimides, or genipin), enzymes (e.g., tyrosinase or peroxidase), physical methods (e.g., vortexing or sonication), or chemical additives (e.g., alcohols [4], surfactants [5], or phospholipids [6]) have been applied to control the kinetics of SF gelation [7].

Gold $(\mathrm{Au})$ is a transition metal that has been widely used for medical purposes, namely as a chrysotherapy for rheumatoid arthritis, or as a chemotherapeutic agent. Au salts are also used to produce Au nanoparticles (AuNPs) that display a high potential in photodynamic and photothermal therapies for cancers, due to their physical and optical properties [8]. Furthermore, AuNPs are used as contrast agents for imaging, carriers for macromolecules, and biosensors [9,10]. Several chemical and physical methods are reported for the production of AuNPs, including those using plant extracts or natural proteins $[9,11]$. In the presence of proteins, $\mathrm{Au}$ salts (the most stable form is $\mathrm{Au}^{3+}$ ) are reduced by amino $\left(-\mathrm{NH}_{2}\right)$ or thiol $(-\mathrm{SH})$ groups to $\mathrm{Au}^{+}$. Afterwards, tyrosine, of which its cresol group displays a strong electron donating property, reduces $\mathrm{Au}^{+}$to $\mathrm{Au}$, and tyrosyl radical is converted to dityrosine [12]. However, when thiol groups are presented, the reduction to Au is prevented due to strong bond formation between $\mathrm{Au}^{+}$and sulfur [13,14].

Due to the presence of amino group containing residues as well as a high content of tyrosine in SF $(\sim 5.75 \%)$ [15], it can be used in the production of AuNPs by a simple procedure and without hazardous reagents $[11,16]$. Moreover, the preparation of hydrogels using thiolated polymers (e.g., thiolated polyethylene glycol) crosslinked by $\mathrm{Au}^{3+}$ was previously reported $[17,18]$.

In this work, we developed SF hydrogel systems using $\mathrm{Au}^{3+}$ salt as a chemical gelator. Both SF and thiol-functionalized SF (tSF) were selected as base matrices to investigate and compare their mechanisms of gel formation in the presence of $\mathrm{Au}^{3+}$. Furthermore, we evaluated the cytocompatibility of the obtained hydrogels to assess their potential for biomedical applications.

\section{Materials and Methods}

\subsection{Materials}

"Nangnoi Srisaket 1" Bombyx mori Thai silk cocoons were kindly provided by Queen Sirikit sericulture center, Srisaket province, Thailand. All chemical reagents were of analytical grade and purchased from Sigma-Aldrich, St. Louis, MO, USA, unless otherwise stated. Culture media and reagents used for biological experiments were supplied from Thermo Fischer Scientific, Waltham, MA, USA. 


\subsection{Preparation of SF and tSF Solutions}

Silk cocoons were cut in half, boiled in $0.02 \mathrm{M} \mathrm{Na}_{2} \mathrm{CO}_{3}$ for $20 \mathrm{~min}$, and washed with deionized (DI) water to remove silk glue. The SF fibers were then dissolved in 9.3 M LiBr at 1:4 ratio (w:v) and incubated at $60{ }^{\circ} \mathrm{C}$ for $4 \mathrm{~h}$. Subsequently, the obtained amber solution was dialyzed against DI water using a dialysis tube with 12-16 kDa MWCO (Sekisui, Osaka, Japan) for $48 \mathrm{~h}$. Finally, the solution was centrifuged at $4{ }^{\circ} \mathrm{C}$ and $9000 \mathrm{rpm}$ for $20 \mathrm{~min}$ to remove debris. The concentration was determined from its dry solid weight. The SF solution was kept at $4{ }^{\circ} \mathrm{C}$ until use.

The introduction of sulfhydryl groups (-SH) into SF was performed according to Monteiro et al. [19] with slight modifications. SF solution of $6 \% w / v$ was dialyzed against $0.1 \mathrm{M}$ sodium phosphate buffer (pH 8.0) at $4{ }^{\circ} \mathrm{C}$ overnight. Different amounts of 2-iminothiolane (2-IT) and 4-dimethylaminopyridine (DMAP) were mixed with the SF solution to obtain a final concentration ranging from 5 to $50 \mathrm{mM}$. Then, the solutions were gently stirred at $37^{\circ} \mathrm{C}$, prior to the dialysis with DI water and determination of the solution concentration by the dry solid weight method. For all further experiments, the $t S F$ solution functionalized with $50 \mathrm{mM}$ 2-IT and DMAP was used because the use of a higher amount of reagents was not possible due to solubility issues.

\subsection{Quantification of Sulfhydryl Groups}

The amount of sulfhydryl groups in tSF was analyzed by Ellman reagent assay. The $1 \%$ tSF solution was mixed with $0.1 \mathrm{M} 5^{\prime}$-dithiobis-(2-nitrobenzoic acid) (DTNB) and $1 \mathrm{mM}$ EDTA. The obtained mixtures were incubated at $37^{\circ} \mathrm{C}$ during $3 \mathrm{~h}$ in the dark and the absorbance was measured at $412 \mathrm{~nm}$. Cysteine was used as standard.

\subsection{Gelation of SF and tSF with $A u^{3+}$}

SF and tSF solutions were mixed with gold (III) chloride trihydrate $\left(\mathrm{HAuCl}_{4} \cdot 3 \mathrm{H}_{2} \mathrm{O}\right)$ to a final concentration of $3 \%$ silk protein and $0.5,1$, and $5 \mathrm{mM} \mathrm{Au}{ }^{3+}$. The mixtures were incubated at $37^{\circ} \mathrm{C}$ for 14 days and the changes were observed occasionally. To investigate the conformation transition, the lyophilized samples obtained from different time-points were analyzed using Fourier-transform infrared spectroscopy (FTIR) (IRPrestige 21, Shimadzu, Kyoto, Japan). The samples were ground with $\mathrm{KBr}$ and punched. The infrared spectra were collected between 4000 to $400 \mathrm{~cm}^{-1}$ in an absorbance mode with $2.0 \mathrm{~cm}^{-1}$ resolution and $1.0 \mathrm{~cm}^{-1}$ interval. The content of secondary structure was determined by Fourier self-deconvolution (FSD) and curve-fitting techniques according to $\mathrm{Hu}$ et al. [20]. The region between 1725 and $1575 \mathrm{~cm}^{-1}$ was firstly deconvoluted using Omnic 8.0 software (Thermo Fisher Scientific, Waltham, MA, USA). The spectral line shape was fitted using Voight function with a half-bandwidth of $10 \mathrm{~cm}^{-1}$ and an enhancement factor of 3.0. Afterwards, the deconvoluted spectrum was curve-fitted using Origin Pro 9.0 software (OriginLab, Northamptom, MA, USA). The beta sheet content was calculated from the sum of area under the peaks located in the 1616-1637 and $1696-1703 \mathrm{~cm}^{-1}$ regions. The amount of other structures, including tyrosine residue, random coil, alpha-helix, and beta turn, were determined from the area under the peaks located within 1595-1615, $1638-1655,1656-1662$, and 1663-1696 cm $\mathrm{cm}^{-1}$, respectively [20].

\subsection{Determination of Bonds and AuNPs Formation in Au-SF or Au-tSF Hydrogels}

The fluorescence emission characteristic of dissociated phenolic hydroxyl groups allows the assessment of the amount of dityrosine by fluorescence measurements [21]. Different amounts of $\mathrm{Au}^{3+}$, ranging from 0.1 to $5 \mathrm{mM}$, were added to $1 \%$ SF or $1 \% \mathrm{tSF}$ solution. The $\mathrm{pH}$ of the solution was maintained at 7.4 using $10 \mathrm{mM}$ HEPES buffer. Fluorescence measurements were performed using a spectrofluorometer (FP-8500, Jasco, Easton, MD, USA) at an excitation wavelength of $320 \mathrm{~nm}$. The emission spectra between 350 and $500 \mathrm{~nm}$ were collected with 2-nm interval. 
The availability of sulfhydryl groups after the addition of $\mathrm{Au}^{3+}$ was examined by the Ellman reagent assay as previously mentioned. Due to the low amount of SH groups present in SF, it was not possible to quantify them in the mixture of Au-SF. All experiments were performed in triplicate.

The formation of AuNPs was confirmed by determining surface plasmon resonance bands obtained from UV-vis absorbance spectra. SF and tSF solutions mixed with different $\mathrm{Au}^{3+}$ amounts were prepared and incubated at room temperature for $3 \mathrm{~h}$ in the dark. Absorption spectra between 300 and $700 \mathrm{~nm}$ were then collected using a microplate reader (Synergy HT, Bio-Tek, Winooski, VT, USA).

\subsection{XPS Analysis}

The hydrogel samples were freeze-dried, finely ground and stored in a desiccator prior to XPS analysis using an Axis ultra DLD spectrometer (Kratos Analytical, Kyoto, Japan) equipped with a monochromatic Al K $\alpha$ x-ray source. Wide scan was performed at binding energy (BE) 0-1200 eV. The spectra of Au4f and S2p were collected in a region of 81-94 and 159-174 eV, respectively. Curve-fitting was performed using Origin Pro 9.0 software. The peaks in $\mathrm{Au}_{4 \mathrm{f} / 2}$ region were assigned into three peaks at approximately 84.0, 84.7, and $85.5 \mathrm{eV}$ [22] and the peaks within $\mathrm{S}_{2} \mathrm{p}_{3 / 2}$ region were at 162.2 and $164.2 \mathrm{eV}$ [23].

\subsection{Micromorphological Assessment}

$\mathrm{Au}-\mathrm{SF}$ and Au-tSF hydrogels prepared with $1 \mathrm{mM} \mathrm{Au}^{3+}$ were freeze-dried, cut and sputter-coated with platinum. Surface feature analysis was visualized using a scanning electron microscope (SEM) (JSM-IT500HR, Jeol, Tokyo, Japan) at 300× and 15,000× magnifications.

\subsection{Analysis of Viscoelastic Properties}

The regenerated SF and $\mathrm{tSF}$ solutions and the mixtures of $3 \% \mathrm{SF}$ or $3 \%$ tSF with 0.5 to $5 \mathrm{mM} \mathrm{Au}^{3+}$ were loaded in the sample holder of a Kinexus Pro+ rheometer (Malvern Instruments, Malvern, UK) equipped with parallel plate geometry with 1-mm gap. Samples were equilibrated at $37^{\circ} \mathrm{C}$ for $10 \mathrm{~min}$ before measurement. Frequency sweep experiments were done and the moduli over $0.01-100 \mathrm{~Hz}$ were collected at a fixed strain of $0.1 \%$. All experiments were done in triplicate.

\subsection{Cell Culture}

L929 mouse fibroblasts were kindly provided by Prof. Dr. Tanapat Palaga, Department of Microbiology, Faculty of Science, Chulalongkorn University. The cells were maintained in Dulbecco's modified eagle medium (DMEM) containing 10\% fetal bovine serum (FBS) and 1\% penicillin/ streptomycin. The subculture was performed when confluency reached approximately $80-90 \%$ using TrypLE Express to detach the adherent cells.

\subsection{Cytocompatibility Evaluation}

Solutions of $3 \% \mathrm{SF}$ or $\mathrm{tSF}$ were sterilized by UV irradiation for $30 \mathrm{~min}$ and $\mathrm{HAuCl}_{4}$ solution was filtered through $0.22 \mu \mathrm{m}$ syringe filter before use. SF and tSF gels were formed in 96-well plates by incubating the $3 \%$ solutions at $37^{\circ} \mathrm{C}$ under a vapor-saturated atmosphere for 7 days. The Au-SF and Au-tSF hydrogels were prepared as previously described.

The hydrogel samples were washed with phosphate buffer saline (PBS), seeded with L929 fibroblasts $\left(10,000\right.$ cells $\left./ \mathrm{cm}^{2}\right)$ and incubated in a humidified $5 \% \mathrm{CO}_{2}$ atmosphere at $37^{\circ} \mathrm{C}$. Medium was changed every other day.

Cell metabolic activity was determined using the MTS assay (Abcam, Cambridge, MA, USA). At each time-point (1, 3, 5, and 7 days), samples were washed with PBS and the MTS reagent in serumand phenol red-free DMEM was added into each well before incubating in the dark at $37^{\circ} \mathrm{C}$ for $3 \mathrm{~h}$. The absorbance values of supernatants were measured at $490 \mathrm{~nm}$ and a blank correction was performed. All experiments were done in quadruplicate. 


\subsection{Statistical Analysis}

The obtained data was analyzed by one-way ANOVA with Bonferroni post-hoc test at $p \leq 0.05$. Statistical analysis was performed using IBM SPSS statistics (Version 22, IBM, Armonk, NY, USA) software.

\section{Results}

\subsection{Thiolation of SF}

Primary amine on silk protein was attached by a sulfhydryl $(\mathrm{SH})$ group by the thiolation reaction made from varying different 2-IT concentration (Figure 1A). The resulting SH groups of $t$ SF solution were determined using the Ellman assay (Figure 1B). It was noticed that an increasing of 2-IT resulted in a greater amount of available $\mathrm{SH}$ groups. Our findings are in an agreement with previous reports that 2-IT introduces SH groups by attaching sulfanyl butanimidine groups to the primary amine on peptide chains [24].
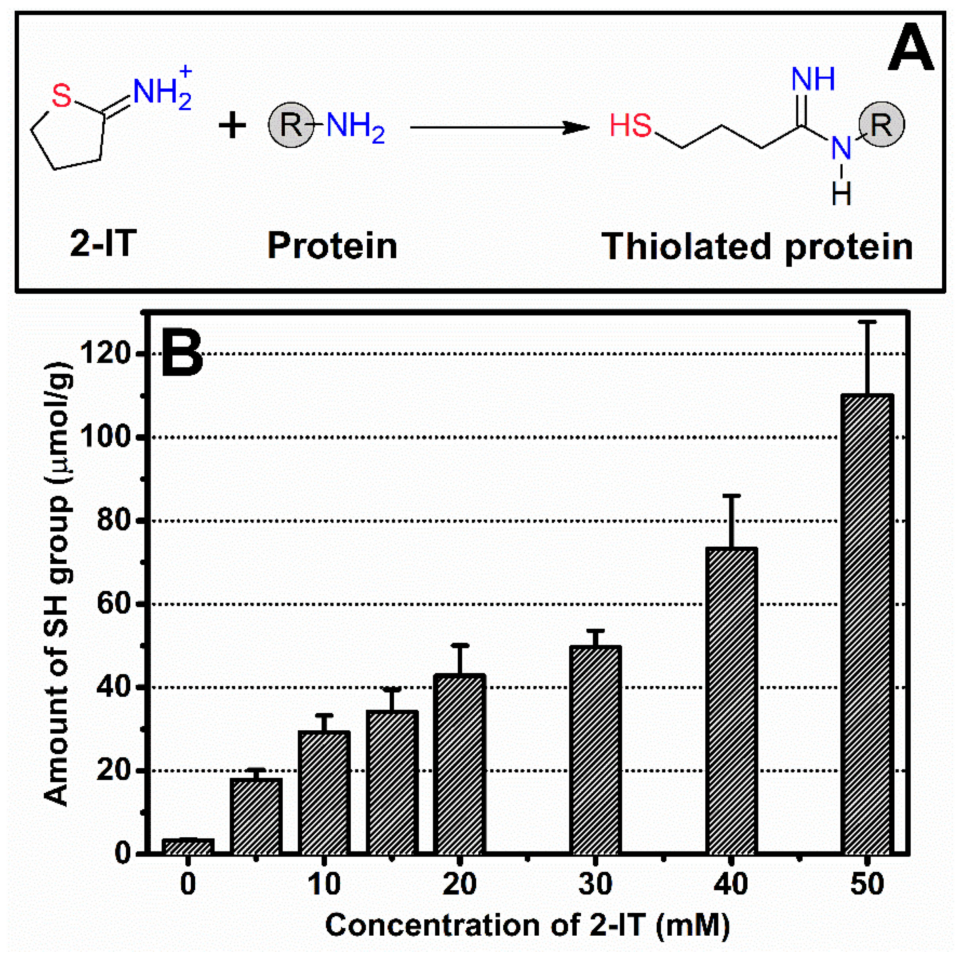

Figure 1. (A) Thiolation reaction of protein using 2-iminothiolane (2-IT) to attach a sulfanyl butanimidine group to a primary amine. (B) Amount of available sulfhydryl groups of thiolated silk fibroin (tSF) determined by the Ellman reagent assay as a function of 2-IT concentration.

\subsection{Formation of $A u-S F$ and $A u$-tSF Hydrogels}

The appearances of regenerated SF and tSF (controls) and their mixtures with $\mathrm{Au}^{3+}$ incubated at $37^{\circ} \mathrm{C}$ for 14 days are presented in Figure 2A. The regenerated SF and tSF solutions formed hydrogels within 7 days, which is in accordance with the increase of beta sheet content (Figure 2B,C). At $0.5 \mathrm{mM}$ $\mathrm{Au}^{3+}$, the Au-tSF mixture (right vial; Figure 2A) formed a hydrogel within 1 day, while the gelation time was longer for the SF group (left vial; Figure 2A). At $1 \mathrm{mM} \mathrm{Au}^{3+}$, both SF and tSF hydrogels were formed in 1 day. Interestingly, distinct appearances of gels were noticed, i.e., the SF gel presented a red-to-purple color, while the tSF gels maintained their initial yellow color. For $5 \mathrm{mM} \mathrm{Au}^{3+}$, both $\mathrm{SF}$ and $\mathrm{tSF}$ formed hydrogels immediately after adding $\mathrm{Au}^{3+}$ into the solutions. However, due to rapid hydrogel formation, a local phase separation occurred, leading to non-homogeneous mixtures for both groups. 

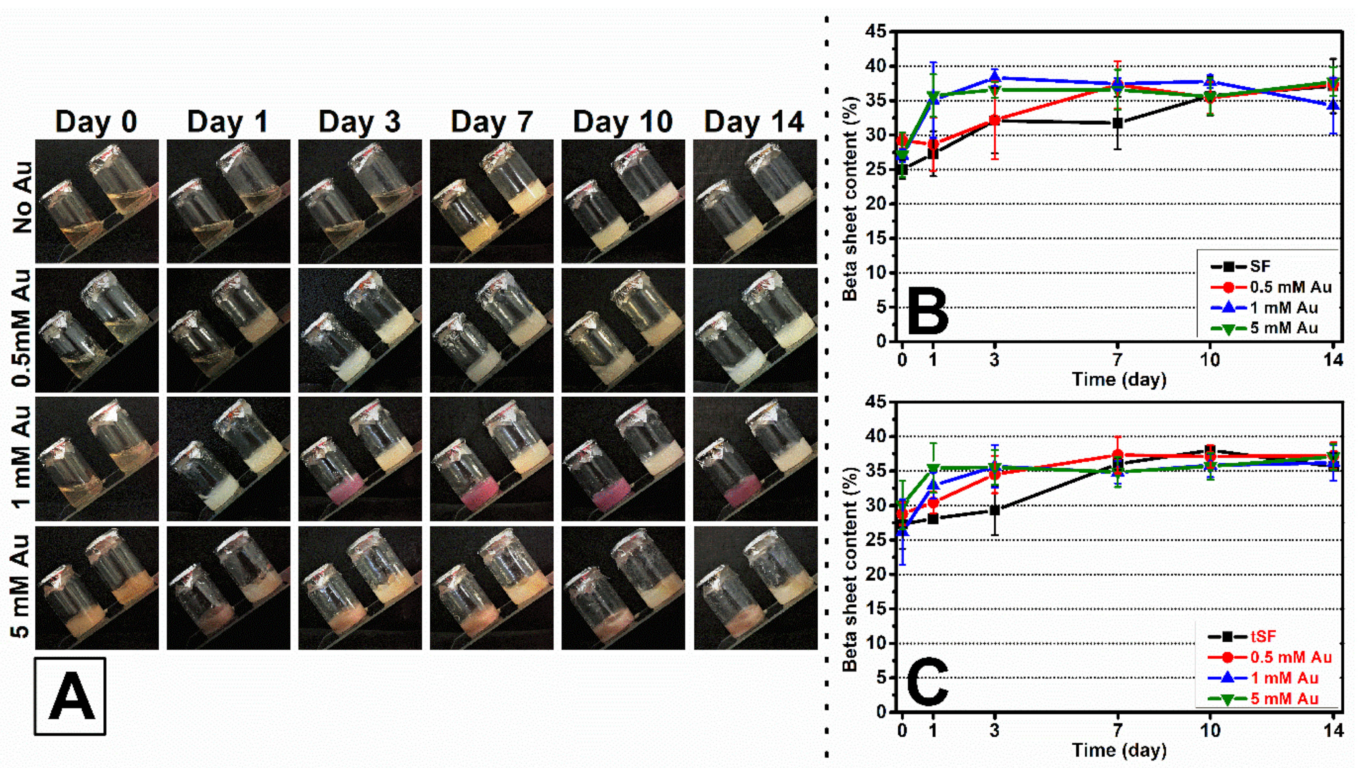

Figure 2. (A) Appearances of regenerated (no $\mathrm{Au}^{3+}$ ) and $\mathrm{Au}^{3+}$-mediated SF (left vial) and tSF (right vial) hydrogels incubated at $37^{\circ} \mathrm{C}$ over 14 days. The amount of beta sheet determined from FTIR spectra using Fourier self-deconvolution (FSD) and curve-fitting techniques of the freeze-dried regenerated SF (B) and tSF (C) at different $\mathrm{Au}^{3+}$ concentrations.

Beta sheet content was determined using FTIR followed by FSD and curve-fitting processes. The gelation of Au-SF mixtures using $0.5 \mathrm{mM} \mathrm{Au}^{3+}$ did not occur on day 1 as observed for the Au-tSF group, but their beta sheet content $(28.7 \pm 3.8 \%$ and $30.4 \pm 1.5 \%$, respectively) were not significantly different. Moreover, SF and tSF with $5 \mathrm{mM} \mathrm{Au}^{3+}$ formed hydrogel immediately after mixing, but the beta sheet content did not change as expected. Beta sheet content was only of $27.1 \pm 3.3 \%$ in SF and 30.1 $\pm 3.5 \%$ in $\mathrm{tSF}$, which were not significantly different from the values obtained for SF and tSF solutions without $\mathrm{Au}^{3+}(25.0 \pm 1.4 \%$ and $27.3 \pm 3.5 \%$, respectively). The structural transition to beta sheet was faster in all $\mathrm{Au}^{3+}$-mediated groups compared to the samples without $\mathrm{Au}^{3+}$. These results imply that the $\mathrm{SF}$ and $\mathrm{tSF}$ structural transition is not the major mechanism of gelation induced by $\mathrm{Au}^{3+}$.

\subsection{Formation of Dityrosine, $A u-S$ Bonds, and AuNPs}

The formation of dityrosine bonds can be examined by fluorescence spectroscopy using excitation and emission wavelengths of 320 and $410 \mathrm{~nm}$, respectively. As shown in Figure 3A, the fluorescence intensity was proportional to $\mathrm{Au}^{3+}$ concentration. The fluorescence signals related to dityrosine formation rapidly increased when $0.5 \mathrm{mM} \mathrm{Au}^{3+}$ and $1 \mathrm{mM} \mathrm{Au}{ }^{3+}$ were added into SF and tSF, respectively. Interestingly, lower concentration of $\mathrm{Au}^{3+}$ could induce dityrosine bonds in SF group, as demonstrated that of the SF group reached maximum intensity at $2 \mathrm{mM} \mathrm{Au}^{3+}$, whereas the $\mathrm{tSF}$ group showed maximum intensity at $3 \mathrm{mM} \mathrm{Au}{ }^{3+}$. 

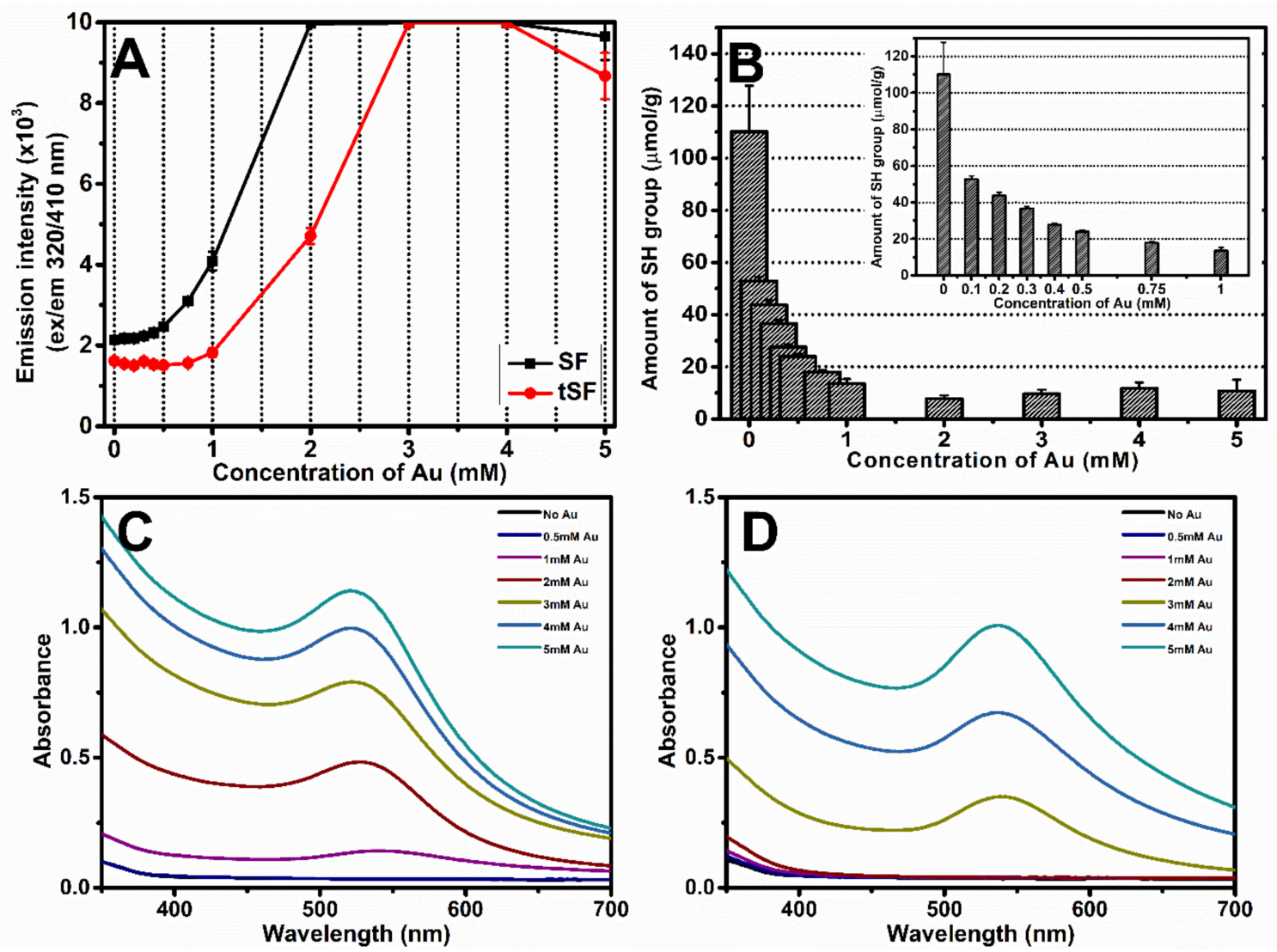

Figure 3. (A) Fluorescence measurements (excitation wavelength $=320 \mathrm{~nm}$, emission wavelength $=$ $410 \mathrm{~nm}$ ) of SF and tSF, corresponding to the formation of dityrosine, after the addition of $\mathrm{Au}^{3+}$ at different concentrations, (B) Amount of available sulfhydryl (SH) groups in tSF in a presence of different amounts of $\mathrm{Au}^{3+}$. The inset shows the results for $\mathrm{Au}^{3+}$ concentrations below $1 \mathrm{mM}$. UV-vis absorbance spectra of the mixtures of (C) $1 \% \mathrm{SF}$ and (D) $1 \% \mathrm{tSF}$ at different $\mathrm{Au}^{3+}$ concentrations, presenting the surface plasmon resonance band of gold nanoparticles (AuNPs).

Addition of $\mathrm{Au}^{3+}$ induced the formation of $\mathrm{Au}-\mathrm{S}$ bonds and reduced the amount of free sulfhydryl groups (SH) on silk fibroin molecules (Figure 3B). Ellman reagent assay indicated a reduction of sulfhydryl groups to $13.6 \mu \mathrm{mol} / \mathrm{g}$ when $1 \mathrm{mM} \mathrm{Au}^{3+}$ was added into tSF solution. Due to the low amount of SH groups in SF solution, the SH group could not be quantified.

The formation of AuNPs was assessed from the UV-vis absorption spectra obtained from Au-SF and Au-tSF mixtures (Figure 3C,D). The appearance of the surface plasmon resonance band between 525 to $535 \mathrm{~nm}$ can be noticed, indicating the formation of AuNPs [25]. At $2 \mathrm{mM} \mathrm{Au}^{3+}$, formation of AuNPs could be detected in SF samples, while it did not occur in tSF group.

\subsection{XPS Analysis of $A u^{3+}-$ Mediated SF and tSF Hydrogels}

After the gelation of the mixtures composed of $1 \mathrm{mM} \mathrm{Au}^{3+}$ and $3 \% \mathrm{SF}$ or $3 \% \mathrm{tSF}$, the samples were lyophilized and the XPS analyses were performed. XPS spectra in Au4f region of the samples are presented in Figure 4A,B. Three peaks were assigned within the $\mathrm{Au}_{4 \mathrm{f}}$ region $(\mathrm{BE}$ 83.0-86.5 eV). The first and last peaks located near 84.0 and $85.5 \mathrm{eV}$ represent the metallic $\mathrm{Au}^{0}$ and $\mathrm{Au}^{3+}$, respectively. The middle peak, which were shifted from the first peak around $0.5-0.6 \mathrm{eV}$, is related to $\mathrm{Au}^{+}$species [22]. The quantification of each chemical state obtained from the calculated areas under peaks is presented in Table 1 . The majority of the $\mathrm{Au}$ state in SF gel was $\mathrm{Au}^{0}$, while both $\mathrm{Au}^{0}$ and $\mathrm{Au}^{+}$were noticed in the tSF gel at the same extent. 

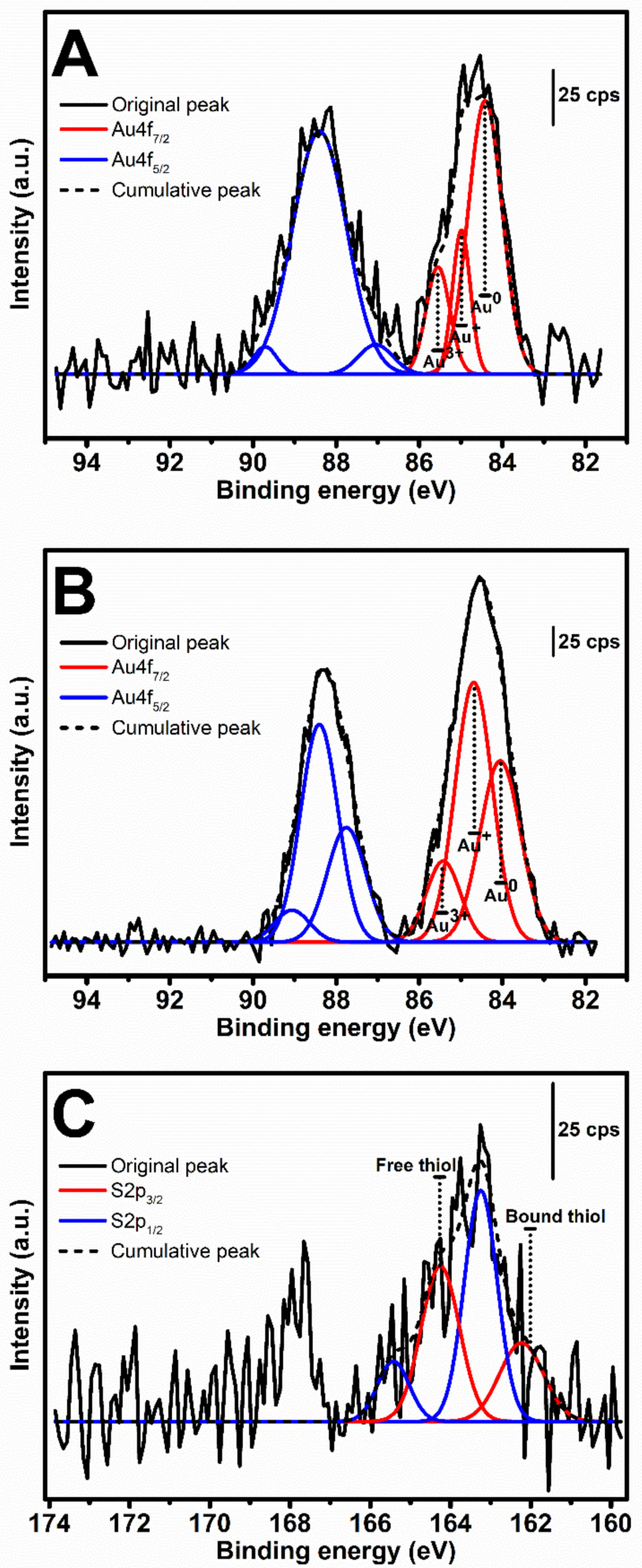

Figure 4. XPS spectra in Au4f region of (A) Au-SF and (B) Au-tSF, and in (C) S2p region of Au-tSF. 
Table 1. Relative percentage of chemical composition determined from XPS spectra within $\mathrm{Au} 4 \mathrm{f}_{7 / 2}$ and S2p region of the lyophilized $1 \mathrm{mM} \mathrm{Au}^{3+}$ with $3 \%$ SF or $3 \%$ tSF samples. Peaks areas of the different chemical states were calculated using Origin Pro 9.0 software.

\begin{tabular}{|c|c|c|c|c|c|}
\hline \multirow{2}{*}{ XPS Region } & \multirow[b]{2}{*}{ Chemical State } & \multicolumn{2}{|c|}{$1 \mathrm{mM} \mathrm{Au}+3 \% \mathrm{SF}$} & \multicolumn{2}{|c|}{$1 \mathrm{mM} \mathrm{Au}+3 \% \mathrm{tSF}$} \\
\hline & & $\begin{array}{c}\mathrm{BE} \\
(\mathrm{eV})\end{array}$ & $\begin{array}{l}\text { Relative Amount } \\
(\%)\end{array}$ & $\begin{array}{c}\mathrm{BE} \\
(\mathrm{eV})\end{array}$ & $\begin{array}{c}\text { Relative Amount } \\
(\%)\end{array}$ \\
\hline \multirow{3}{*}{$\mathrm{Au} 4 \mathrm{f}_{7 / 2}$} & $\mathrm{Au}^{0}$ & 84.4 & 31.7 & 84.0 & 21.9 \\
\hline & $\mathrm{Au}^{+}$ & 84.9 & 8.9 & 84.6 & 28.9 \\
\hline & $\mathrm{Au}^{3+}$ & 85.5 & 8.8 & 85.4 & 8.3 \\
\hline \multirow{2}{*}{$\mathrm{S} 2 \mathrm{p}_{3 / 2}$} & Bound S & \multirow{2}{*}{\multicolumn{2}{|c|}{ N/A }} & 162.2 & 18.2 \\
\hline & Free S & & & 164.2 & 31.4 \\
\hline
\end{tabular}

The analysis of free and bound thiol groups by XPS is shown in Figure 4C and Table 1. Due to the absence of thiol groups in SF, the spectrum in S2p region could not be obtained. The S2p spectrum of $\mathrm{tSF}$ was assigned into two components based on the spin-orbit splitting doublet, $\mathrm{S}_{2} \mathrm{p}_{3 / 2}$ (162.2 and $164.2 \mathrm{eV}$ ) and S2 $\mathrm{p}_{1 / 2}(163.2$ and $165.4 \mathrm{eV})$. The first component located at $162.2 \mathrm{eV}$ was regarded as bound (chemisorbed) thiol group, while the peak at $164.2 \mathrm{eV}$ corresponded to the free or weakly bound (physisorbed) sulfur [23].

\subsection{SEM Analysis}

The freeze-dried $1 \mathrm{mM} \mathrm{Au}-3 \% \mathrm{SF}$ and $1 \mathrm{mM} \mathrm{Au}-3 \%$ tSF hydrogels were sectioned and their microstructures were analyzed by SEM (Figure 5). The Au-SF gel exhibited a leaf-like morphology and interconnected pores with size larger than $50 \mu \mathrm{m}$ (Figure 5A). At a high magnification, distributed particles, with approximately $20 \mathrm{~nm}$ diameter, over the gel matrices were observed (Figure 5B). This could be an evidence of the formation of AuNPs. Different microstructures were noticed for tSF samples. The Au-tSF gel showed a micro- or nano-fibrous structure with smaller interconnected pores (Figure 5C), and without the presence of particles (Figure 5D).

\section{$1 \mathrm{mM} \mathrm{Au}-3 \%$ SF $1 \mathrm{mM} \mathrm{Au}-3 \% \mathrm{tSF}$}
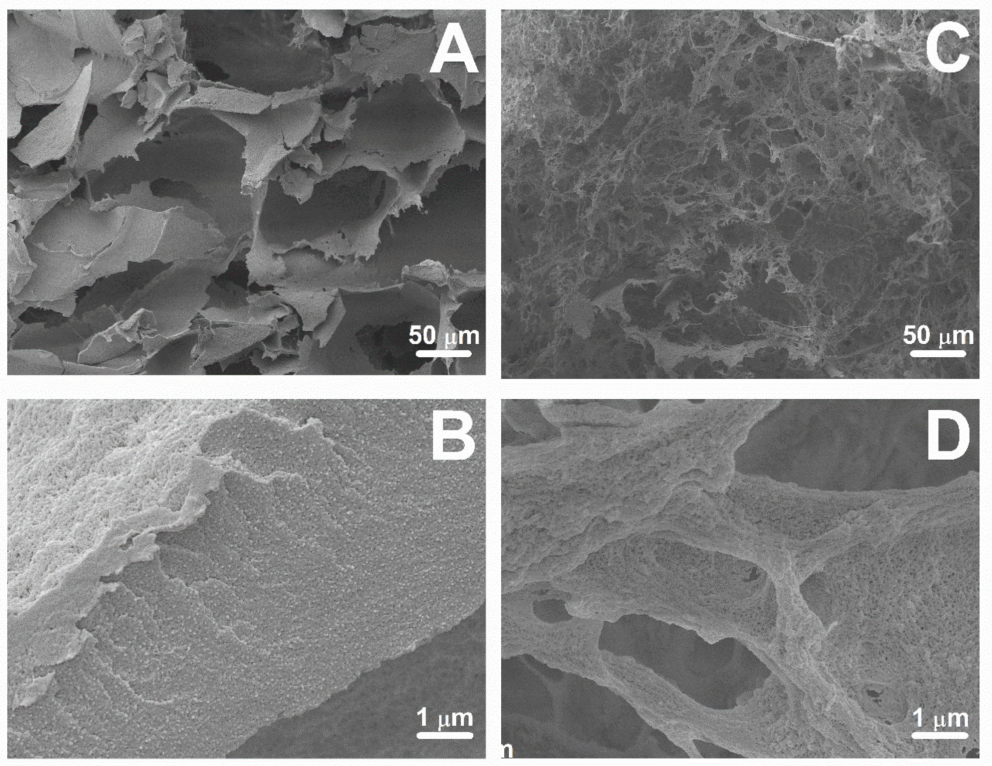

Figure 5. SEM images of the lyophilized $1 \mathrm{mM} \mathrm{Au-3} \% \mathrm{SF}(\mathbf{A}, \mathbf{B})$ and $1 \mathrm{mM}$ Au-3\% tSF (C,D) hydrogels. 


\subsection{Viscoelastic Properties of $A u^{3+}$-SF and tSF Gels}

The complex $\left(G^{*}\right)$, storage $\left(G^{\prime}\right)$ and viscous $\left(G^{\prime \prime}\right)$ moduli over a range of frequency from 0.01 to $100 \mathrm{~Hz}$ of the samples are shown in Figure 6. Regenerated SF and tSF solutions were used as controls. For all samples, the moduli were constant over the frequency from 0.01 to $10 \mathrm{~Hz}$ before steeply rising until $100 \mathrm{~Hz}$. G' and G" of regenerated SF and $\mathrm{tSF}$ were almost equal which corresponded to their solution state. The addition of $0.5 \mathrm{mM} \mathrm{Au}^{3+}$ increased $\mathrm{G}^{*}$ in the range of 1-20 Pa for SF samples, while the higher $\mathrm{G}^{*}$ values (15-50 Pa) were obtained in tSF group. An increasing of $\mathrm{Au}^{3+}$ concentration resulted in gradually higher moduli. However, the moduli of Au-tSF samples were similar regardless of $\mathrm{Au}^{3+}$ concentration. Presumably, $\mathrm{Au}^{3+}$ at the concentrations greater than $0.5 \mathrm{mM}$ did not significantly affect the viscoelastic properties of the obtained gels.
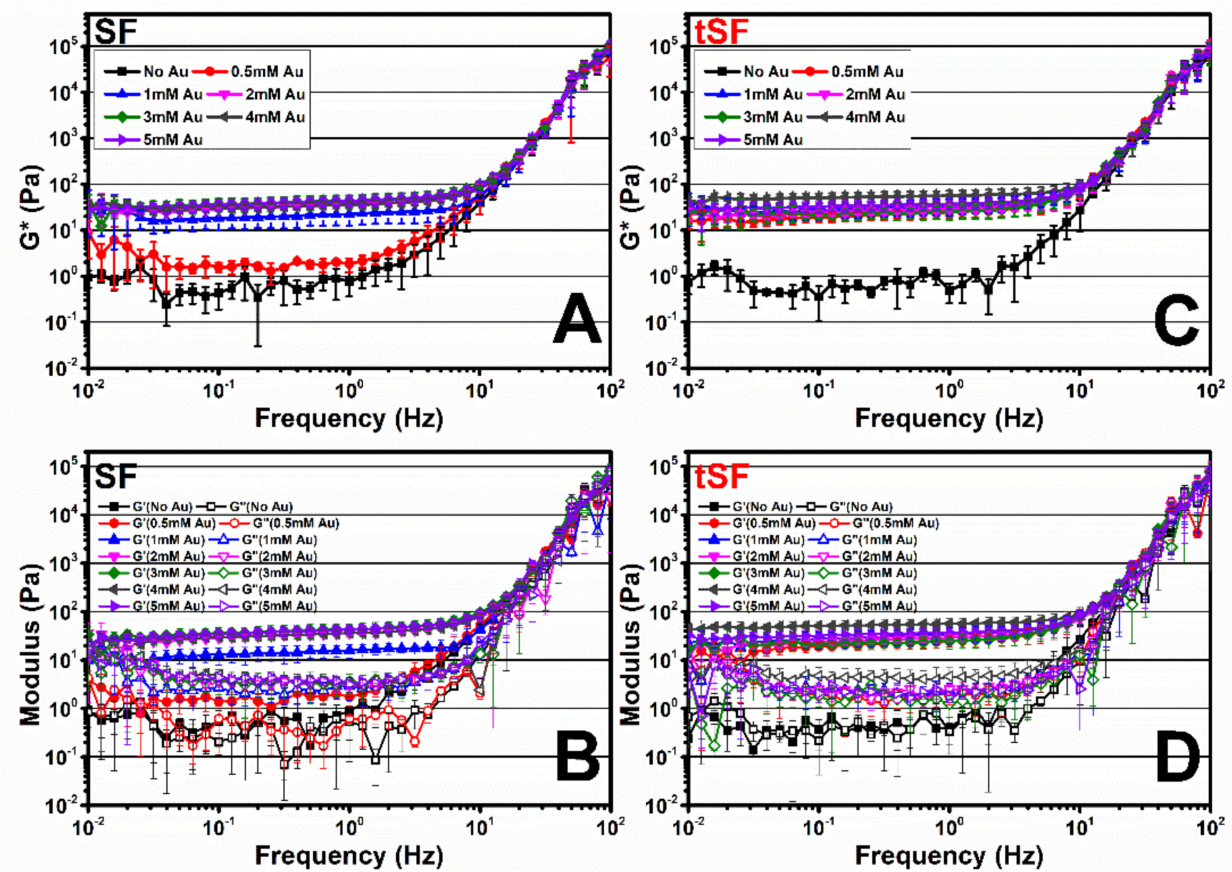

Figure 6. Frequency sweep experiments $\left(0.01-100 \mathrm{~Hz}\right.$ with $0.1 \%$ fixed strain, $\left.37^{\circ} \mathrm{C}\right)$ of regenerated $\mathrm{SF}$ and the mixtures of $3 \% \mathrm{SF}(\mathbf{A}, \mathbf{B})$ or $\mathrm{tSF}(\mathbf{C}, \mathbf{D})$ with different $\mathrm{Au}^{3+}$ concentrations $(1-5 \mathrm{mM})$. $(\mathbf{A}, \mathbf{C})$ Complex modulus $\left(G^{*}\right),(\mathbf{B}, \mathbf{D})$ storage modulus $\left(G^{\prime}\right)$, and viscous modulus $\left(G^{\prime \prime}\right)(n=3)$.

\subsection{Cytocompatibility Evaluation of $\mathrm{Au}^{3+}-\mathrm{SF}$ and $t S F$ Hydrogels}

L929 fibroblasts were cultured on SF and tSF hydrogels prepared with different $\mathrm{Au}^{3+}$ concentrations $(0,0.5,1$, and $5 \mathrm{mM})$. Cells cultured on tissue culture plates (TCPs) were used as references. The metabolic activity of cells cultured on Au-SF and Au-tSF hydrogels in all $\mathrm{Au}^{3+}$ concentrations increased over the time course of 7 days culture period (Figure 7). However, a significant low metabolic activity at day 7 was noticed for both SF and tSF samples. Interestingly, without an addition of $\mathrm{Au}^{3+}$, a decrease of metabolic activity was observed in SF group, whereas tSF group displayed the higher metabolic activity. Despite metabolic activities were not as high as the ones obtained from the control TCP, SF, and $\mathrm{tSF}$ hydrogels with $\mathrm{Au}^{3+}$ supported the proliferation of L929, indicating the cytocompatibility of these hydrogels. 


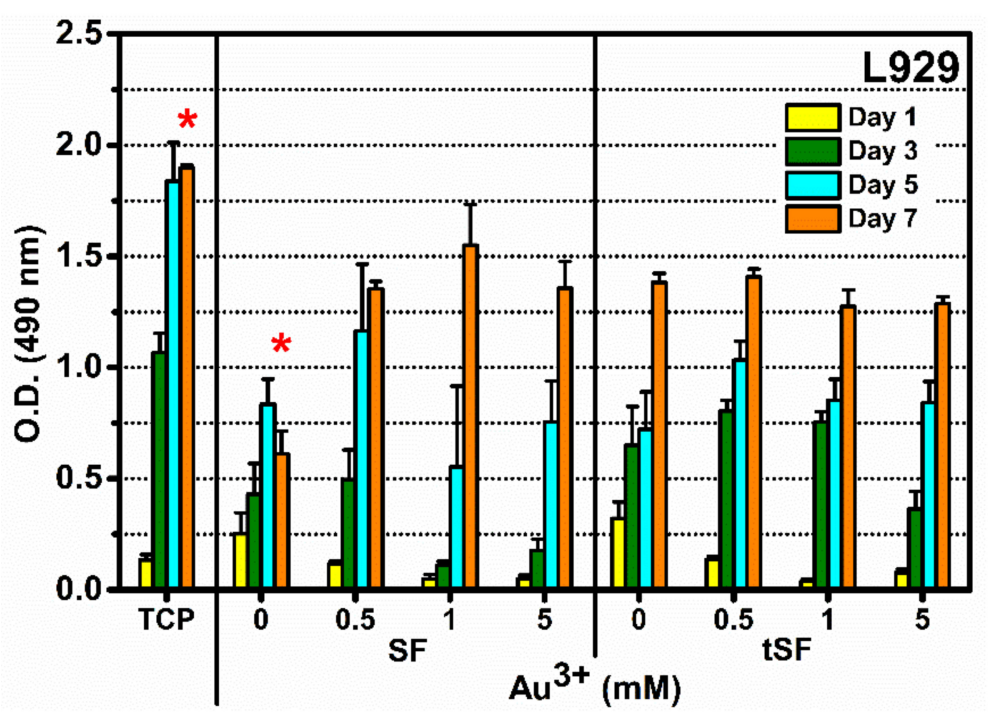

Figure 7. Cytocompatibility of SF and tSF hydrogels, and Au-SF and Au-tSF hydrogels with L929 rate fibroblasts. Cells were seeded on the hydrogels at 10,000 cells $/ \mathrm{cm}^{2}$ and cultured for 7 days. Cell metabolic activity was assessed by MTS assay $(n=4)\left(\mathrm{TCP}=\right.$ tissue culture plate). ${ }^{*}$ indicates statistical differences at $p \leq 0.05$.

\section{Discussion}

Different strategies to induce the SF gelation have been proposed, namely crosslinking agents and techniques that stimulate the self-assembly process. In this work, $\mathrm{Au}^{3+}$, a metallic ion, was used as a promoter agent to induce SF and tSF gelation. The gelation mechanisms and the cytocompatibility of the resulting hydrogels were investigated.

The formation of $1 \mathrm{mM} \mathrm{Au}{ }^{3+}-3 \%$ SF hydrogels was accompanied with an obvious color change (from yellow to purple red), which can be related to the AuNPs formation (Figure 2A). The presence of AuNPs was confirmed by the surface plasmon resonance band at $525 \mathrm{~nm}$ which increased with higher concentrations of $\mathrm{Au}^{3+}$ (Figure 3C,D). The XPS results also indicated that $\mathrm{Au}^{0}$ is the predominant state (Figure 4) and SEM images showed distributed nanoparticles over the hydrogel matrix (Figure 5B). The presence of dityrosine bonds was studied by spectrofluorometry and the emission intensity increased with higher amounts of $\mathrm{Au}^{3+}$ added (Figure 3A). It can be proposed that, after the addition of $\mathrm{HAuCl}_{4}$, amino $\left(-\mathrm{NH}_{2}\right)$ groups could act as reducing agents converting $\mathrm{Au}^{3+}$ to $\mathrm{Au}^{+}$. Afterwards, a reduction to $\mathrm{Au}$ occurs by accepting an electron from the tyrosine side chain. Hence, two tyrosyl radicals form a covalent dityrosine $[12,14]$.

In the case of regenerated SF, the spontaneous gelation of SF is related to its self-assembly characteristic [3]. A less ordered random coil structure present in the solution evolves into a highly stable beta sheet conformation due to hydrophobic interactions and hydrogen bonding between repetitive peptide sequences. The increase in beta sheet structures results in stronger interactions of the peptide chains, leading to the gel formation.

The changes of the secondary structures from random coil to beta sheet did not support the kinetics of Au-mediated SF gelation. The presence of $\mathrm{Au}^{3+}$ cannot directly induce the development of protein secondary structures, which did not correspond with gel formation (Figure 2B,C). However, a more rapid increase of beta sheet conformation was observed in the presence of $\mathrm{Au}^{3+}$. It can be speculated that both the generation of protons due to the reduction of $\mathrm{Au}^{3+}$ and the dityrosine formation may interfere with the local $\mathrm{pH}$. The $\mathrm{pH}$, therefore, shifted towards the isoelectric point of SF (4.59-5.06), leading to SF chain aggregation and subsequent gel formation as it was previously reported by Matsumoto et al. [3].

tSF was synthesized by a simple chemical reaction using 2-IT and the obtained functionalized protein was mixed with $\mathrm{Au}^{3+}$. The resulting hydrogels maintained the initial color of the solution, 
indicating the absence of AuNPs formation (Figure 2A). The addition of $\mathrm{Au}^{3+}$ resulted in a decrease of available thiol groups (Figure 3B), confirming the disulfide (S-S) and gold-sulfide (Au-S) bonding. The XPS analysis also showed a higher relative amount of $\mathrm{Au}^{+}$(Figure 4 and Table 1) and the formation of nanoparticulate features was not noticeable in the SEM images (Figure 5D). These results are in agreement with Jung et al. [13] who reported that thiol-presenting molecules, namely cysteine, homocysteine, and glutathione, prevent Au reduction and NPs formation. Like Au-SF hydrogels, the conformational transition of Au-tSF did not occur along with the gelation but the transition to beta sheet conformation was accelerated by the presence of gold. The generation of protons from the oxidation reaction of -SH to S-S or Au-S is proposed, resulting in a decrease of local $\mathrm{pH}$ and hence the kinetics of tSF gelation are enhanced. The proposed mechanisms of $\mathrm{Au}^{3+}$-mediated SF and $\mathrm{tSF}$ gelation are depicted in Figure 8.

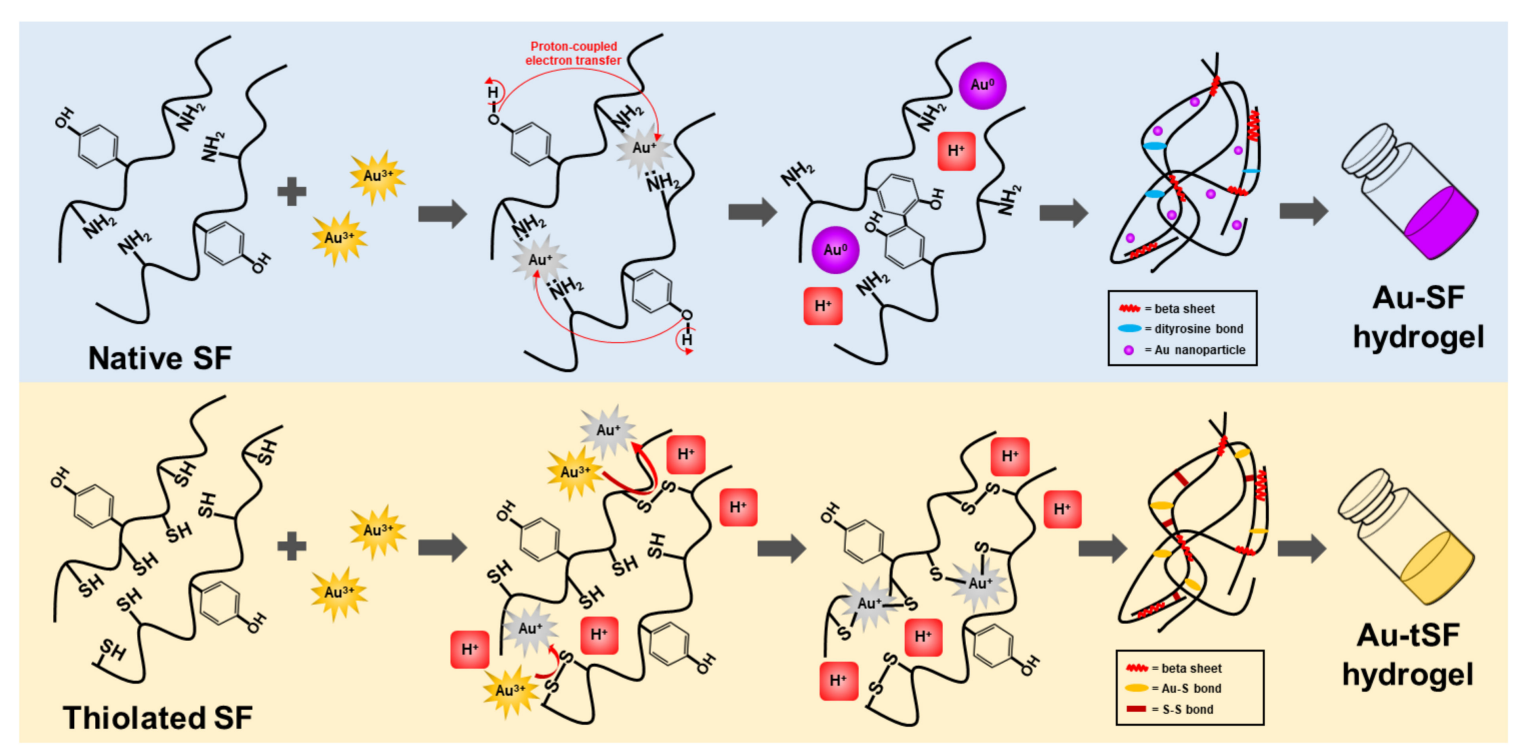

Figure 8. Proposed gelation mechanism of Au-SF and Au-tSF hydrogels. For SF, amino groups of protein side chains firstly coordinate with $\mathrm{Au}^{3+}$ and reduce to $\mathrm{Au}^{+}$. Tyrosine residues then donate electrons via proton-coupled transfer reaction to $\mathrm{Au}^{+}$and reduce to $\mathrm{Au}$, leading to dityrosine bonding and AuNPs formation. Protons $\left(\mathrm{H}^{+}\right)$are generated and induce SF beta sheet transition. For $\mathrm{tSF}$, thiol groups donate electrons to $\mathrm{Au}^{3+}$, resulting in $\mathrm{Au}^{+}$, and form disulfide bonds. Subsequently, $\mathrm{Au}^{+}$form bonds with available thiol groups without further reduction. The generation of $\mathrm{H}^{+}$from S-S and Au-S bonds results in a beta sheet formation of tSF.

At the highest tested concentration of $\mathrm{Au}^{3+}(5 \mathrm{mM})$, an immediate gelation occurred after mixing. However, non-homogeneous gels with partial precipitation were obtained (Figure 2A). Furthermore, there was no noticeable color change, due to AuNPs formation. This could relate to the high $\mathrm{H}^{+}$from $\mathrm{HAuCl}_{4}$, which decreased the $\mathrm{pH}$ of the mixtures, leading to the protonation of tyrosine. Since $\mathrm{pK}_{\mathrm{a}}$ of tyrosine is approximately 10 , the proton-coupled electron transfer to $\mathrm{Au}^{+}$is more difficult when the phenolic group of tyrosine is protonated [12].

The thiolation of SF and the presence of $\mathrm{Au}^{3+}$ resulted in a faster gelation compared with the kinetics of the gelation of SF with $\mathrm{Au}^{3+}$, especially at low $\mathrm{Au}^{3+}$ amounts. As shown in Figure 6, the modulus of $0.5 \mathrm{mM} \mathrm{Au}^{3+}$-tSF is higher than those of SF. This could imply the immediate formation of Au-S bonding in Au-tSF hydrogels due to click chemistry [18]. While the formation of dityrosine bonds, which is proposed as a major mechanism of Au-SF hydrogels, required a longer time [12].

Cytocompatibility results of Au-SF and Au-tSF hydrogels were performed using L929 cell line as a model. Normal proliferation of cells was noticed for all samples (Figure 7), indicating that the cytocompatibility of hydrogels was maintained even the presence of $\mathrm{Au}^{3+}$. Indeed, SF is well-known for its biocompatibility [2], but tSF remained inadequately studied. Our study investigated the compatibility 
of tSF with the cultured cells, confirming its potential as a biomaterial. Schedle et al. [26] confirmed the cytotoxicity of metallic ions, including $\mathrm{HAuCl}_{4}$, and they reported the $\mathrm{TC} 50$ (50\% toxicity levels) of $\mathrm{Au}^{3+}$ was $0.077 \mathrm{mM}$. However, our developed hydrogels containing higher $\mathrm{Au}^{3+}$ amounts showed no toxicity for L929. In addition, SF and tSF might possess a preventive effect against the cytotoxicity of the metallic ion by the side chains of amino acid residues which act as reducing, stabilizing, or chelating molecules [27].

\section{Conclusions}

$\mathrm{Au}^{3+}$ is herein proposed to induce the gelation of regenerated SF and $\mathrm{tSF}$ and their underlying mechanisms were proposed. The addition of $\mathrm{Au}^{3+}$ significantly reduced the gelation time of SF and $\mathrm{tSF}$, but the different gel microstructures were noticed, indicating different gelation mechanisms. Dityrosine bonding and the formation of AuNPs were proposed for $\mathrm{Au}^{3+}$-mediated SF hydrogels with the purple-red color. The presence of thiol groups in tSF prevented the reduction of $\mathrm{Au}^{+}$to $\mathrm{Au}$ because of the strong Au-S interaction. The conformational transition of SF and tSF from random coil to beta sheet is proposed as a downstream mechanism after the generation of protons from dityrosine formation (for SF gel) or S-S or Au-S bonding (for tSF gel) and subsequent reduction of the local $\mathrm{pH}$, leading to chain aggregation.

$\mathrm{Au}^{3+}$-mediated SF and tSF hydrogels showed good cytocompatibility when L929 cells were cultured at their surfaces. Further studies will be conducted to characterize in detail the biological performance of the developed hydrogels.

Author Contributions: Conceptualization, C.L., H.F., S.D., and N.M.N.; data curation, C.L. and H.F.; formal analysis, C.L.; funding acquisition, R.L.R., S.D., and N.M.N.; investigation, C.L.; methodology, C.L., H.F., and N.M.N.; project administration, S.D. and N.M.N.; resources, R.L.R., S.D., and N.M.N.; supervision, H.F., S.D., and N.M.N.; validation, H.F., S.Y., S.D., and N.M.N.; visualization, C.L. and H.F.; writing-original draft, C.L.; writing-review and editing, H.F., S.Y., R.L.R., S.D., and N.M.N. All authors have read and agreed to the published version of the manuscript.

Funding: This article has been prepared with the support of REMIX Project, funded by the European Union's Horizon 2020 Research and Innovation programme under the Maria Sklodowska-Curie grant agreement N.778078. Chavee Laomeephol acknowledges the PhD grants supported by Chulalongkorn University for "The 100th Anniversary Chulalongkorn University Fund for Doctoral Scholarship" and "The 90th Anniversary Chulalongkorn University Fund (Ratchadaphiseksomphot Endowment Fund)". Authors also acknowledge the financial support from FCT (Portuguese Foundation for Science and Technology) for the project PTDC/CTM-BIO/4388/2014 - SPARTAN, the Northern Portugal Regional Operational Programme (NORTE 2020), under the Portugal 2020 Partnership Agreement, through the European Regional Development Fund (FEDER) (NORTE-01-0145-FEDER-000023 FROnTHERA) and the NORTE 2020 Structured Project, co funded by Norte2020.

Conflicts of Interest: The authors have no conflicts of interest to declare.

\section{References}

1. Murphy, A.R.; Romero, I.S. 8-Biochemical and biophysical properties of native Bombyx mori silk for tissue engineering applications. In Silk Biomaterials for Tissue Engineering and Regenerative Medicine; Kundu, S.C., Ed.; Woodhead Publishing: Cambridge, UK, 2014; pp. 219-238.

2. Altman, G.H.; Diaz, F.; Jakuba, C.; Calabro, T.; Horan, R.L.; Chen, J.; Lu, H.; Richmond, J.; Kaplan, D.L. Silk-based biomaterials. Biomaterials 2003, 24, 401-416. [CrossRef]

3. Matsumoto, A.; Chen, J.; Collette, A.L.; Kim, U.-J.; Altman, G.H.; Cebe, P.; Kaplan, D.L. Mechanisms of Silk Fibroin Sol-Gel Transitions. J. Phys. Chem. B 2006, 110, 21630-21638. [CrossRef]

4. Kaewprasit, K.; Kobayashi, T.; Damrongsakkul, S. Thai silk fibroin gelation process enhancing by monohydric and polyhydric alcohols. Int. J. Biol. Macromol. 2018, 118, 1726-1735. [CrossRef]

5. Chantong, N.; Damrongsakkul, S.; Ratanavaraporn, J. Gelation Process and Physicochemical Properties of Thai Silk Fibroin Hydrogels Induced by Various Anionic Surfactants for Controlled Release of Curcumin. J. Surfactants Deterg. 2019, 22, 1395-1407. [CrossRef]

6. Laomeephol, C.; Guedes, M.; Ferreira, H.; Reis, R.L.; Kanokpanont, S.; Damrongsakkul, S.; Neves, N.M. Phospholipid-induced silk fibroin hydrogels and their potential as cell carriers for tissue regeneration. J. Tissue Eng. Regen. Med. 2020, 14, 160-172. [CrossRef] 
7. Kapoor, S.; Kundu, S.C. Silk protein-based hydrogels: Promising advanced materials for biomedical applications. Acta Biomater. 2016, 31, 17-32. [CrossRef]

8. Shaw, C.F. Gold-Based Therapeutic Agents. Chem. Rev. 1999, 99, 2589-2600. [CrossRef]

9. Elahi, N.; Kamali, M.; Baghersad, M.H. Recent biomedical applications of gold nanoparticles: A review. Talanta 2018, 184, 537-556. [CrossRef]

10. Yadav, P.; Singh, S.P.; Rengan, A.K.; Shanavas, A.; Srivastava, R. Gold laced bio-macromolecules for theranostic application. Int. J. Biol. Macromol. 2018, 110, 39-53. [CrossRef]

11. Lakshmeesha Rao, B.; Gowda, M.; Asha, S.; Byrappa, K.; Narayana, B.; Somashekar, R.; Wang, Y.; Madhu, L.N.; Sangappa, Y. Rapid synthesis of gold nanoparticles using silk fibroin: Characterization, antibacterial activity, and anticancer properties. Gold Bull. 2017, 50, 289-297. [CrossRef]

12. Si, S.; Bhattacharjee, R.R.; Banerjee, A.; Mandal, T.K. A Mechanistic and Kinetic Study of the Formation of Metal Nanoparticles by Using Synthetic Tyrosine-Based Oligopeptides. Chem. A Eur. J. 2006, 12, 1256-1265. [CrossRef]

13. Jung, Y.L.; Park, J.H.; Kim, M.I.; Park, H.G. Label-free colorimetric detection of biological thiols based on target-triggered inhibition of photoinduced formation of AuNPs. Nanotechnology 2015, 27, 055501. [CrossRef]

14. Xu, Y.; Sherwood, J.; Qin, Y.; Crowley, D.; Bonizzoni, M.; Bao, Y. The role of protein characteristics in the formation and fluorescence of Au nanoclusters. Nanoscale 2014, 6, 1515-1524. [CrossRef]

15. Kaewprasit, K.; Promboon, A.; Kanokpanont, S.; Damrongsakkul, S. Physico-chemical properties and in vitro response of silk fibroin from various domestic races. J. Biomed. Mater. Res. Part B Appl. Biomater. 2014, 102, 1639-1647. [CrossRef]

16. Zhou, Y.; Chen, W.; Itoh, H.; Naka, K.; Ni, Q.; Yamane, H.; Chujo, Y. Preparation of a novel core-shell nanostructured gold colloid-silk fibroin bioconjugate by the protein redox technique at room temperature. Chem. Commun. 2001, 23, 2518-2519. [CrossRef]

17. Casuso, P.; Pérez-San Vicente, A.; Iribar, H.; Gutiérrez-Rivera, A.; Izeta, A.; Loinaz, I.; Cabañero, G.; Grande, H.-J.; Odriozola, I.; Dupin, D. Aurophilically cross-linked “dynamic" hydrogels mimicking healthy synovial fluid properties. Chem. Commun. 2014, 50, 15199-15201. [CrossRef]

18. Casuso, P.; Odriozola, I.; Pérez-San Vicente, A.; Loinaz, I.; Cabañero, G.; Grande, H.-J.; Dupin, D. Injectable and Self-Healing Dynamic Hydrogels Based on Metal(I)-Thiolate/Disulfide Exchange as Biomaterials with Tunable Mechanical Properties. Biomacromolecules 2015, 16, 3552-3561. [CrossRef]

19. Monteiro, N.; Martins, A.; Pires, R.; Faria, S.; Fonseca, N.A.; Moreira, J.N.; Reis, R.L.; Neves, N.M. Immobilization of bioactive factor-loaded liposomes on the surface of electrospun nanofibers targeting tissue engineering. Biomater. Sci. 2014, 2, 1195-1209. [CrossRef]

20. Hu, X.; Kaplan, D.; Cebe, P. Determining Beta-Sheet Crystallinity in Fibrous Proteins by Thermal Analysis and Infrared Spectroscopy. Macromolecules 2006, 39, 6161-6170. [CrossRef]

21. Malencik, D.A.; Anderson, S.R. Dityrosine as a product of oxidative stress and fluorescent probe. Amino Acids 2003, 25, 233-247. [CrossRef]

22. Karpenko, A.; Leppelt, R.; Plzak, V.; Behm, R.J. The role of cationic Au3+ and nonionic Au0 species in the low-temperature water-gas shift reaction on $\mathrm{Au} / \mathrm{CeO} 2$ catalysts. J. Catal. 2007, 252, 231-242. [CrossRef]

23. Castner, D.G.; Hinds, K.; Grainger, D.W. X-ray Photoelectron Spectroscopy Sulfur 2p Study of Organic Thiol and Disulfide Binding Interactions with Gold Surfaces. Langmuir 1996, 12, 5083-5086. [CrossRef]

24. Singh, R.; Kats, L.; Blättler, W.A.; Lambert, J.M. Formation of N-Substituted 2-Iminothiolanes When Amino Groups in Proteins and Peptides Are Modified by 2-Iminothiolane. Anal. Biochem. 1996, 236, 114-125. [CrossRef]

25. Mulvaney, P. Surface Plasmon Spectroscopy of Nanosized Metal Particles. Langmuir 1996, 12, 788-800. [CrossRef]

26. Schedle, A.; Samorapoompichit, P.; Rausch-Fan, X.H.; Franz, A.; Füreder, W.; Sperr, W.R.; Sperr, W.; Ellinger, A.; Slavicek, R.; Boltz-Nitulescu, G.; et al. Response of L-929 Fibroblasts, Human Gingival Fibroblasts, and Human Tissue Mast Cells to Various Metal Cations. J. Dent. Res. 1995, 74, 1513-1520. [CrossRef]

27. Dickerson, M.B.; Sandhage, K.H.; Naik, R.R. Protein- and Peptide-Directed Syntheses of Inorganic Materials. Chem. Rev. 2008, 108, 4935-4978. [CrossRef]

(C) 2020 by the authors. Licensee MDPI, Basel, Switzerland. This article is an open access article distributed under the terms and conditions of the Creative Commons Attribution (CC BY) license (http://creativecommons.org/licenses/by/4.0/). 